\title{
Asthma in pregnancy complicated by iatrogenic pulmonary oedema
}

\author{
C.C. Hardy, P. Lorigan, A. Ratcliffe and K.B. Carroll \\ Departments of Cardiothoracic and Anaesthetic Medicine, Wythenshawe Hospital, Southmoor Road, Manchester \\ $M 239 L T, U K$.
}

\begin{abstract}
Summary: We report a unique case of near fatal acute pulmonary oedema developing with intravenous ritodrine, given in an attempt to suppress premature labour. The novel aspect of the case is that the patient had also been treated in the previous week with high dose nebulized beta-agonists for an episode of acute severe asthma, demonstrating that this idiosyncratic reaction to beta-adrenergic agents only occurs with the intravenous route of administration. The management of acute severe asthma occurring in pregnancy is discussed with a review of previous literature regarding possible mechanisms of beta ${ }_{2}$-agonist-induced pulmonary oedema.
\end{abstract}

\section{Introduction}

Breathlessness is a common symptom during pregnancy, but is not thought to be due to increased airways resistance. ${ }^{1}$ Nevertheless, asthmatic patients do occasionally deteriorate ${ }^{2}$ and can pose therapeutic problems. Intravenous beta $_{2}$-adrenoreceptor agonists including ritodrine, ${ }^{3}$ salbutamol, ${ }^{4,5}$ terbutaline, ${ }^{6}$ fenoterol, ${ }^{7}$ and isoxuprine ${ }^{8}$ have been found to cause acute pulmonary oedema, occasionally fatal, when used as tocolytic agents, particularly with concurrent administration of corticosteroids to accelerate fetal lung maturation.

We report a patient with severe asthma during pregnancy, ventilated and treated uneventfully with nebulized salbutamol and corticosteroids, who, upon receiving parenteral ritodrine for premature labour, developed near fatal pulmonary oedema.

\section{Case report}

A 23 year old woman, 26 weeks pregnant, was admitted with acute severe asthma. Despite regular inhaled salbutamol, beclomethasone, disodium cromoglycate and oral aminophylline, she had become increasingly symptomatic throughout pregnancy. In the past, she had required multiple admissions for her asthma, but had never required positive pressure ventilation. There was a previous history of episodic angiooedema. She was pyrexial $38^{\circ} \mathrm{C}$, with a tachycardia of 140 beats/min, and $25 \mathrm{mmHg}$ of paradox, peak

Correspondence: C.C. Hardy, M.B., B.S., Hope Hospital, Eccles Old Road, Salford M6 8HD, UK.

Accepted: 23 January 1989 expiratory flow rate (PEFR) was 70 litres $/ \mathrm{min}$ and arterial blood gases $\left(\mathrm{FiO}_{2}=70 \%\right)$ showed $\mathrm{pH}=7.23$, $P_{O_{2}}=163 \mathrm{mmHg}(21.7 \mathrm{kPa}), P \mathrm{PO}_{2}=45 \mathrm{mmHg}(6 \mathrm{kPa})$ and $\mathrm{HCO}_{3}=18 \mathrm{mmol} / \mathrm{l}$. A chest radiograph showed only hyperinflation (Figure 1).

Despite intensive bronchodilator treatment she deteriorated, the $\mathrm{PCO}_{2}$ rising to $55 \mathrm{mmHg}(7.3 \mathrm{kPa})$, and within one hour of admission elective endotracheal intubation and ventilation was undertaken.

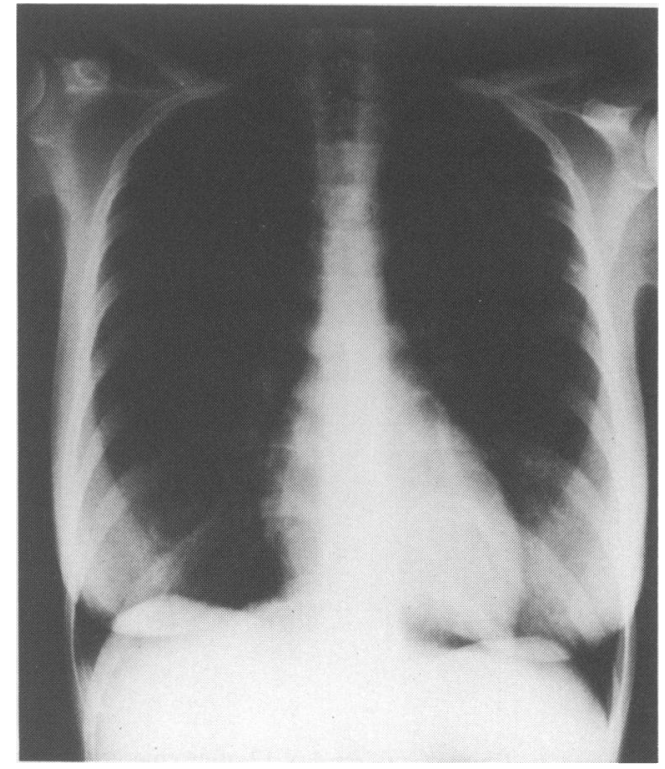

Figure 1 Chest X-ray taken on admission.

(C) The Fellowship of Postgraduate Medicine, 1989 
In addition to positive pressure ventilation (Engstrom Erica, Sweden) at a minute volume of 9.6 litres, nebulized salbutamol $(5 \mathrm{mg})$ and ipratropium bromide $(0.25 \mathrm{mg}) 4$ hourly, hydrocortisone $200 \mathrm{mg} 4$ times a day and intravenous aminophylline achieving plasma levels of $11 \mathrm{mg} / \mathrm{l}$ were continued. The initial peak inspiratory pressure was $55 \mathrm{~cm} \mathrm{H}_{2} \mathrm{O}$, falling to $30 \mathrm{~cm}$ $\mathrm{H}_{2} \mathrm{O}$ after 24 hours.

The $\mathrm{PCO}_{2}$ was maintained at $30 \mathrm{mmHg}(4 \mathrm{kPa})$, approximating to 'normal' levels during pregnancy', the $\mathrm{PO}_{2}$ averaging $100 \mathrm{mmHg}\left(\mathrm{FiO}_{2}=40 \%\right)$. She was weaned off the ventilator after 8 days, and maintained on nebulized salbutamol $5 \mathrm{mg}, 5$ times daily and oral prednisolone.

At 10 days, uterine contractions were apparent, with a closed cervix for which intravenous ritodrine, $10 \mathrm{mg} / \mathrm{h}$ was instituted $(50 \mathrm{mg} / 500 \mathrm{ml}$ of alternating saline and dextrose). The following day the dose of ritodrine was increased to $20 \mathrm{mg} / \mathrm{h}$ resulting in an immediate increased heart rate from 100 to 144 beats/min. Forty hours after commencing ritodrine, she became acutely breathless, heart rate 170 beats/ $\min , P_{2}=73 \mathrm{mmHg}(9.7 \mathrm{kPa}), P_{C O}=68 \mathrm{mmHg}$ $(9.1 \mathrm{kPa})\left(\mathrm{FiO}_{2}=60 \%\right)$, requiring emergency reintubation, when copious pulmonary oedema fluid was aspirated. A chest X-ray confirmed florid pulmonary oedema (Figure 2), and central venous pressure was $12 \mathrm{~cm} \mathrm{H}_{2} \mathrm{O}$. Positive pressure ventilation and frusemide, with discontinuation of the ritodrine, produced a rapid clinical and radiographic improvement.

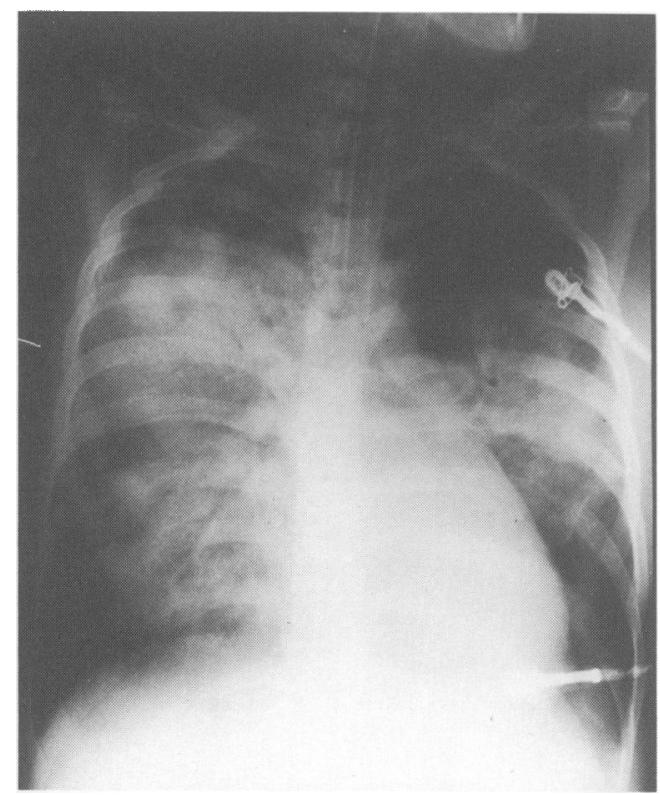

Figure 2 Chest X-ray on day 12 after emergency reintubation.
In the 48 hours prior to this episode there had not been any change in haematocrit, haemoglobin, or serum albumin with a positive fluid balance of 1.3 litres recorded, occurring within the previous 24 hours only. Electrocardiography demonstrated the evolution of $T$ wave inversion in leads 1,2 , AVL, V3-V6, with echocardiographic evidence within 12 hours of onset of the pulmonary oedema of normal left ventricular function (ejection fraction $60 \%$ ), and a small pericardial effusion. Cardiac enzymes were transiently elevated.

Within 12 hours, the membranes ruptured spontaneously to reveal meconium stained liquor, intravenous Syntocinon was commenced and 8 hours later a stillborn male child was delivered. The patient was extubated 12 hours post-delivery and discharged 1 week later, the electrocardiogram showing persistent $\mathrm{T}$ wave inversion; the echocardiograph was normal.

\section{Discussion}

Beta $_{2}$-agonists are effective in inhibiting premature labour, but may precipitate acute pulmonary oedema. The first case was published in $1977^{9}$ with over 70 subsequent reported cases, with 8 deaths. A particularly high incidence $(5 \%)$ was reported in one series consequent upon the infusion of terbutaline. ${ }^{6}$ Only 3 previously reported cases have required positive pressure ventilation, the majority responding within 24 hours to withdrawal of the tocolytic agent and diuretic therapy. ${ }^{10}$

The underlying mechanism of the pulmonary oedema is not clear (for review see ref 10 ), reported cases having been associated with high and normal pulmonary capillary wedge pressure. ${ }^{11}$ Beta ${ }_{2}$-agonists stimulate anti-diuretic hormone, the reninaldosterone axis, and may increase cardiac output by $40 \%$, potentially causing fluid overload when cardiac output is already increased by up to $40 \%$ due to the pregnant state. Predisposition to pulmonary oedema in twin pregnancies $\left(33 \%\right.$ of reported cases $\left.{ }^{6}\right)$ with beta-agonist administration in saline ${ }^{12}$ and with concomitant administration of corticosteroids $(63 \%$ of reported cases) supports this mechanism.

No direct effect of beta-agonists on pulmonary vascular permeability has been reported, but direct cardiotoxicity is suggested. ${ }^{13}$ Up to $55 \%$ of patients treated with ritodrine develop transient $\mathrm{T}$ wave inversion, independently of induced hypokalaemia. Subendocardial myocardial infarction has also been reported. ${ }^{13}$

In our case the enzyme rise was probably secondary to insertion of a central line, although with a persistent electrocardiographic abnormality, a small infarct can- 
not be excluded. The normal echocardiogram, however, militates against left ventricular dysfunction as the cause of the pulmonary oedema.

To our knowledge, pulmonary oedema complicating intravenous beta $a_{2}$-agonist therapy is unique to pregnancy and the puerperium with no reported cases consequent upon their administration by either the nebulized or intravenous routes, in the treatment of acute asthma. Although larger intravenous doses are generally recommended for tocolytic therapy, the dosage schedules overlap, and pulmonary oedema has

\section{References}

1. Weinberger, S.E., Weiss, S.T., Cohen, W.R., Weiss, J.W. \& Johnson, T.S. Pregnancy and the lung. Am Rev Respir Dis 1980, 121: 559-581.

2. Greenberger, P.A. \& Patterson, R. Beclomethasone dipropionate for severe asthma during pregnancy. Ann Intern Med 1983, 98: 478-480.

3. MacLennan, F.M., Thomson, M.A.R., Rankin, R., Terry, P.B. \& Adey, G.D. Fatal pulmonary oedema associated with the use of ritodrine in pregnancy. $\mathrm{Br} J$ Obstet Gynaecol 1985, 92: 703-705.

4. Whitehead, M.I., Mander, A.M., Hertogs, K., Williams, R.M. \& Pettingale, K.W. Acute congestive cardiac failure in a hypertensive woman receiving salbutamol for premature labour. $\mathrm{Br} \mathrm{Med} J$ 1980, 2: 1221-1222.

5. Davies, A.E. \& Robertson, M.J.S. Pulmonary oedema after the administration of intravenous salbutamol and ergometrine. Br J Obstet Gynaecol 1980, 87: 539-541.

6. Katz, M., Robertson, P.A. \& Creasy, R.K. Cardiovascular complications associated with terbutaline treatment for preterm labour. Am J Obstet Gynecol 1981, 139: 605-608.

7. Guernsey, B.G., Villareel, Y., Synder, M.D. \& Gabert, H.A. Pulmonary oedema associated with the use of betamimetic agents in preterm labour. Am J Hosp Pharm 1981, 38: 1942-1948. been reported at doses commonly employed in the treatment of acute asthma. ${ }^{4-6}$

A severe deterioration of asthma during pregnancy is likely to be treated with corticosteroids, with the potential development of pulmonary oedema, if betaagonists are administered intravenously. Since nebulized and intravenous beta-agonists are equally effective, ${ }^{14}$ it would seem preferable to use the inhaled route in the treatment of asthma during pregnancy, to circumvent this potentially fatal iatrogenic complication.

8. Nagey, D.A. \& Crenshaw, M.C. Pulmonary complications of isoxuprine therapy in the gravida. Obstet Gynecol 1981, 59 (Suppl): 33s-42s.

9. Kubli, F. In: Anderson, A. (ed.) Proceedings of the Study Group on Preterm Labour. Royal College of Obstetricians and Gynaecologists, London, 1977, pp. 218-220.

10. Hawker, F. Pulmonary oedema associated with Beta 2-sympathomimetic treatment of premature labour. Anaesth Intensive Care 1984, 12: 143-151.

11. Mabie, W.C., Pernoll, M.L., Witty, J.B. \& Biswas, M.K. Pulmonary oedema induced by betamimetic drugs. South Med J 1983, 76: 1354-1360.

12. Philipsen, T., Eriksen, P.S. \& Lynggard, F. Pulmonary oedema following ritodrine - saline infusion in premature labour. Obstet Gynecol 1981, 58: 304-308.

13. Hendrick, S.K., Keroes, J. \& Katz, M. Electrocardiographic changes associated with ritodrine induced maternal tachycardia and hypokalaemia. Am J Obstet Gynecol 1986, 154: 921 -923.

14. Lawford, P., Jones, B.J.M. \& Milledge, J.S. Comparison of intravenous and nebulised salbutamol in initial treatment of severe asthma. Br Med J 1978, 1: 84. 